\title{
IMMEDIATE REPLACEMENT OF THE CONDYLE FOLLOWING DISARTICULATION RESECTION BY COSTOCHONDRAL GRAFT USING STEREOLITHOGRAPHIC MODEL
}

\author{
Abdullah Essam M. Al-Hady*, Ahmed Mokhtar El-Mardenly**, Mamdouh Sayed***, \\ Mohamed Khalifa Zayet ${ }^{* * * *}$ and Khaled M. Abd El-Ghany ${ }^{* * * * *}$
}

\begin{abstract}
Purpose: Immediate replacement of the mandibular condyle is sometime required when the mandibular condyle is involved in pathology. This study was designed to evaluate immediate replacement of the condyle using costochondral graft following disarticulation.

Patients and Methods: This study included 11 patients, where costochondral graft was used for immediate condylar replacement following disarticulation, the condylar replacement articulated against the preserved disc. The follow up was 2 months. Assessment was conducted immediately postoperatively by radiographic examination and 2 months by direct questioning, and clinical observation.
\end{abstract}

Results: Eleven patients suffered from benign and locally aggressive lesions of the mandibles were presented in this study, there were no complications in all patients, there was no open bite, normal range of mandibular opening, the occlusion and facial form was restored. Radiographic outcome showed normal position of the replaced condyle in the glenoid fossa.

Conclusions: Immediate reconstruction of the condylar unit with costochondral graft is a viable technique combining ease of surgery and a high success rate. Keeping in mind this was the primary stage of reconstruction and the patient will pass the second stage constructing the body area by anterior iliac crest grafting via transcutaneous approach

\footnotetext{
* B.D.S., M.Sc, (Cairo University)

** Professor of Oral and Maxillofacial Surgery, Oral and Maxillofacial Surgery Department, Faculty of Oral and Dental Medicine, Cairo University

*** Assistant Professor of Oral and Maxillofacial Surgery, Oral and Maxillofacial Surgery Department, Faculty of Oral and Dental Medicine, Cairo University.

**** Assistant Professor of Oral and Maxillofacial Surgery, Oral Radiology Department, Faculty of Oral and Dental Medicine, Cairo University.

***** Assistant Professor, Head of Rapid Prototyping Department, Central Metallurgical Research and Development Institute, Ministry of Scientific Research and Technology
} 


\section{INTRODUCTION}

Defects of the mandible may result from treatment of benign and malignant tumours, congenital abnormalities, trauma, infections, and osteoradionecrosis. Jaw resection following pathological lesions has been reported as the most common cause of mandibular defects requiring reconstruction in Oral and Maxillofacial Surgery. The ideal goal of reconstruction is to achieve sufficient anatomical bulk (height and width) of the mandible that will accommodate implant insertion and adequate muscle attachments to allow for normal form and function.

Reconstruction of mandibles after ablative surgery for benign tumours still poses a challenge for the profession. The resulting defects are rather big, but usually would not require composite flaps because the soft tissues are not resected along with the mandible. These defects would best be treated with bone grafts, preferably immediately following the resection. Most patients suffering from odontogenic tumours are also relatively young as compared to the group of patients suffering from malignant tumors. The need for adequate primary reconstruction is, therefore, even more pressing since most of the patients are in the midst of their active life. Different techniques of reconstruction of the mandible have been performed with various levels of success.

Disarticulation resection of the mandible results in a complex deformity that has significant potential to affect facial appearance and oral function. It is expected that a successful reconstruction of such a deformity will restore the facial form, maintain the premorbid dental relationship, and preserve mouth opening. Ideally, this would be accomplished at the time of ablative surgery.

There are numerous publications describing personal favorable experiences, and yet a truly flawless reconstructive result is not easy to attain. First, it is difficult to replicate the complex threedimensional conformation of the mandible.
Second, any aberration in its structural alignment may very likely lead to functional disturbance like malocclusion or temporomandibular joint (TMJ) syndrome. Situations like extensive bone resection, temporomandibular joint involvement, or severely distorted bony contour would add to the difficulties in a reconstructive task. The advent of computer-guided surgical planning based on computed tomography (CT) data and by the aid of rapid prototyping techniques allowed for virtual preoperative planning of different surgical scenarios.

\section{MATERIAL AND METHODS}

Eleven Patients were selected diagnosed with benign tumour approaching to the condyle and free of any systemic disease that would interfere with bone or soft tissue healing. Patients were examined for facial asymmetry, intraoral buccal and lingual expansion, condition of related teeth, the occlusion and maximum mouth opening.

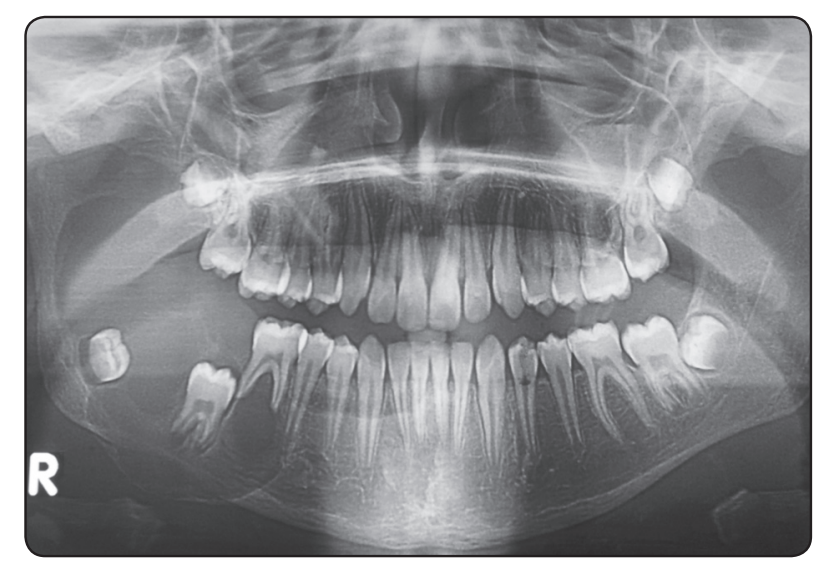

Intraoral incisional biopsy from the lesion was taken to determine the type of the lesion.

Radiographic examination by panorama and multislice CT.

Computer-aided planning was done using specialized software for surgical planning and simulation.

For creation a virtual surgical model. The data of virtual mode transferred to to the machine to 
fabricat computer-guided stereolithographic model from a plastic material using 3D printing machine. The model was used to adapt and pre-contour a titanium reconstruction plate before surgery.

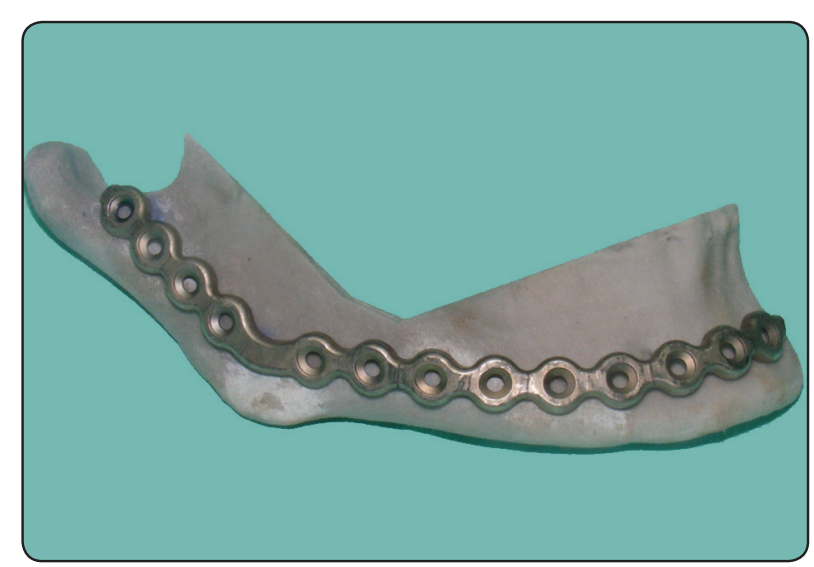

\section{Surgical Technique}

Disarticulation resection of the odontogenic tumor was done under G.A through an extra-oral submandibular incision. A rib graft was harvested and adjusted guided by the stereolithographic model and fixed to the pre-contoured reconstruction plate to be placed in glenoid fossa (hybrid technique),which fixed to remaining stump of the mandible. Patient placed in MMF for two weeks postoperativly

\section{Clinical Follow-up}

- Patients were examined clinically for facial swelling \& symmetry, maximum mouth opening, occlusion and temporomandibular disorders weekly for the first month and then at 3 and 6 months postoperatively.

\section{Post operative clinical and radiographic Follow-up}

- Radiographically, all patients were subjected to immediate postoperative digital panoramic radiograph (1:1) and computed tomography (CT) of the mandible to assess position of both the reconstruction plate and costochondral graft.

- Clinically the following parameters will be assessed:
- Extraoraly: Facial symmetry and facial contour

- Intraorally: Occlusion and midline position

\section{Virtual post operative assesment}

- Post operative CT images in a DICOM format were imported into the software, 3D virtual image of mandible post resection and reconstruction will be created. A virtual 3D image of the deformed mandible preoperatively after making mirror image from normal side and establishing a normal contoured mandible (planned mandible) will imported to the post resection CT software, the two virtual image of the mandible will superimposed on each other using normal side of the mandible as a guide and refrence

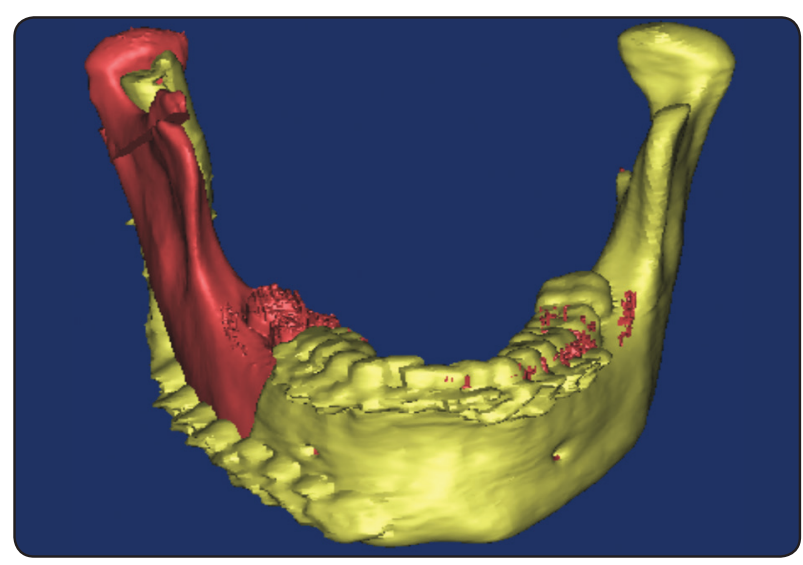

\section{RESULTS}

We have operated on a total of eleven patients six males and five female whose ages ranged between $4 \& 35$.

\section{Intraoperative Findings}

- Stereolithographic Model : had perfect replica of mandible before lesion affection in all cases that enabled accurate and precise guidance of bending reconstruction plate and adjustment position of rib graft.

The pre-bent reconstruction plates together allowed accurate seating of the rib graft in to its proper place in the glenoid fossa. Standard IMF was enough on the distal segment during plate fixation. 


\section{- Postoperative Findings}

- All patients enjoyed an excellent and repeatable occlusion after and removal of IMF

\section{Clinical and Radiographic Results}

- After the persistent swelling subsided almost 1 month after the surgery, all other patients enjoyed normal facial contours that were judged by the patients and observers to be highly symmetric and esthetic.

- Immediate postoperative panoramic radiographs showed restoration of the original contours of the mandible

- Postoperative CT scan showed a highly symmetric mandible that restored the original mandibular contour and rib graft seated in the glenoid fossa.

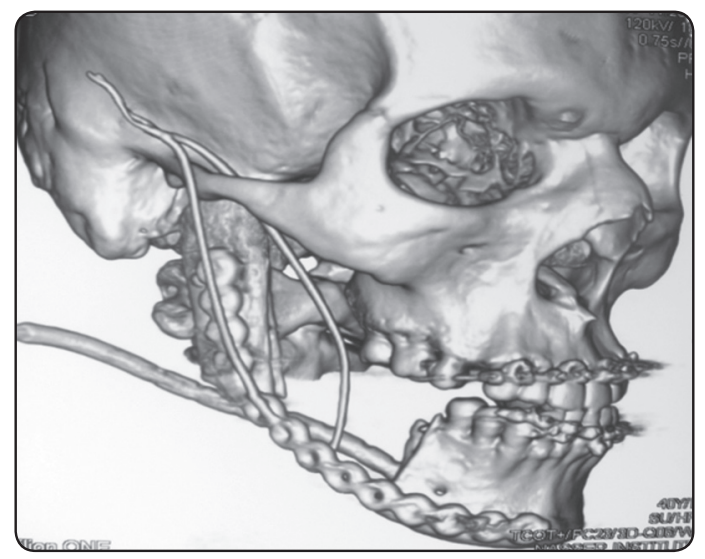

\section{DISCUSSION}

Disarticulation resections of the mandible are a specific form of segmental resection that is indicated in a variety of pathologic conditions that affect the mandible and contiguous structures.

This hybrid technique of mandibular reconstruction to include the ramus condyle unit is felt to have the following advantages over other techniques: Attempts to reconstruct the mandibular body, angle, ramus, and condyle immediately following segmental resection with a through-and through wound have generally met with low success rates unless a microvascular free graft is used. Wound breakdown usually occurs intraorally, over the mandibular body portion of the reconstruction, because this is where the mucosa is thinnest and most poorly vascularised make a watertight closure difficult. ${ }^{22}$

Another advantage of such a technique is that at the primary surgery there is usually excellent visibility to place thecostochondral graft in optimal position in relationship to the meniscus and the glenoid fossa, and to attach it adequately to the bone plate.

The superior part of the ramus unit and the condyle are immediately reconstructed with a costochondral graft, while the body and angle region are reconstructed immediately with a reconstruction plate andthen secondarily reconstructed with corticocancellous blocks from the iliac crest.

Non-vascular grafts remain the preferred choice for most maxillofacial surgeons specially when reconstructing defects resulting from resection of benign tumors where enough soft tissue remains to obtain primary closure and where probably the patient did not receive any kind of radiotherapy that would compromise the blood supply of the recipient site. Compared to vascularized bone grafts, nonvascularized grafts offer the advantages ofless donor site morbidity, less hospitalization time and better shape and volume.

\section{SUMMARY AND CONCLUSION}

The current study was designed to evaluate the role and efficacy of stereolithographic model in reconstruction of disarticulated Mandibular defects. Eleven patients suffering from benign tumour approaching to the condyle were selected from the outpatient clinic of the Oral and Maxillofacial Surgery department, Faculty of Oral and Dental Medicine, Cairo University.

The clinical parameters were facial symmetry, maximum mouth opening and occlusion, while the radiographic parameters were plate 
adaptability and rib position in glenoid fossa. Clinical parameters were assessed up to 2 months postoperatively, radiographic parameters were assessed on specialized software for surgical planning and simulation using pre operative and post operative CT .

Clinical parameters showed excellent results in all patients with satisfied facial symmetry for the patients, regain normal mouth opening and occlusion.

The results of this short term follow-up after resection and reconstruction Stereolithographic Model created by computer guided technology was of great benefit in disarticulation resection cases regarding pre-pending of reconstruction plate and help in planning and positioning of rib graft in glenoid fossa.

The greatest disadvantages of using SLA models are the time and cost involved in making the models.

\section{REFRENCESE}

- Abou-ElFetouh A, Barakat A, Abdel-Ghany K: Computerguided rapid-prototyped templates for segmental mandibular osteotomies: a preliminary report.Int J Med Robot 2011; 7:187

- $\quad$ Adamo AK, Szal RL: Timing, results, and complications ofmandibular reconstructive surgery: Report of 32 cases. J OralSurg

- Engroff SL: Fibula flap reconstruction of the condyle in disarticulation resections of the mandible: A case report and review of the technique. Oral Surg Oral Med Oral Pathol Oral RadiolEndod 2005;100:661

- $\quad$ Eric R. Carison: Disarticulation resection of the mandible a prospective review of 16 cases, American Association of Oral and Maxillofacial Surgeons, J Oral Maxillofacsurg 2002;60:176-181

- Fuhrmann RA, Frohberg U, Diedrich PR: Treatment prediction with three-dimensional computer tomographic skull models. Am J OrthodDentofacialOrthop 1994; 106:156
- Hallermann W, Olsen S, Bardyn T, Taghizadeh F, Banic A, lizuka T: A new method for computer-aided operation planning for extensive mandibular reconstruction, Plast Reconstr Surg 2006;117:2431

- Hannen EJ: Recreating the original contour in tumor deformed mandibles for plate adapting, Int $\mathrm{J}$ Oral MaxillofacSurg 2006 35:183

- $\quad$ Lee JW, Fang JJ, Chang LR \& Yu CK: Mandibular defect reconstruction with the help of mirror imaging coupled with laser stereolithographic modeling technique. J Formos Med Assoc 2007; 106:244

- Marx RE, Saunders TR: Reconstruction and rehabilitation ofcancer patients, in Fonseca R, Davis WH (eds): ReconstructivePreprosthetic Oral and Maxillofacial Surgery. Philadelphia, PA,Saunders, 1986, pp 347-428

- Ndukwe KC, Aregbesola SB, Ikem IC, Ugboko VI, Adebiyi $\mathrm{KE}^{1}$, Fatusi OA, Owotade FJ, Braimah RO: Reconstruction of Mandibular Defects Using Nonvascularized Autogenous Bone Graft in Nigerians. Nigerian journal of surgery 2014;20:87

- Pogrel MA, Schmidt BL: Reconstruction of the MandibularRamus/Condyle Unit Following Resection of Benign and Aggressive Lesions of the Mandible: J Oral MaxillofacSurg 2007;65:801-804

- Southard TE, Morris JH, Southard KA, Zeitler DL: A threedimensional system for planning orthognathic surgery. A case report. J Am Dent Assoc 1994;125:452

- Toro C, Robiony M, Costa F, ZermanN ,Politi M: Feasibility of preoperative planning using anatomical facsimile models for mandibular reconstruction. Head Face Med 2007;3:5

- Ueda K, Tajima S, Oba S, Omiya Y, Byun SI \& Okada M: Mandibular contour reconstruction with three-dimensional computer-assisted models, Ann PlastSurg 2001; 46:387

- Warnke PH, Springer IN, Wiltfang J, Acil Y, Eufinger H, Wehmöller M, Russo PA, Bolte H, Sherry E, Behrens E, Terheyden H: Growth and transplantation of a custom vascularised bone graft in a man. Lancet2004; 364:766-70

- Watzinger F, Wanschitz F, Rasse M: Computer-aided surgery in distraction osteogenesis of the maxilla and mandible. Int J Oral MaxillofacSurg 1999;28:171 